\title{
MEASUREMENT OF REGIONAL ENVIRONMENTAL EFFICIENCY IN CHINA BASED ON THE SUPER-EFFICIENCY SBM MODEL
}

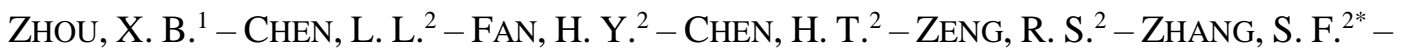 \\ CHEN, S. F. ${ }^{2}$ \\ ${ }^{1}$ School of Economics \& Management, Northwest University, Xi'an 710069, China \\ ${ }^{2}$ College of Statistics and Mathematics, Zhejiang Gongshang University, Hangzhou 310018, \\ China \\ *Corresponding author \\ e-mail: zhshangfeng@163.com; phone+86-571-2800-8096 \\ (Received $18^{\text {th }}$ Mar 2019; accepted $17^{\text {th }}$ May 2019)
}

\begin{abstract}
This paper measures the regional environmental efficiency in China by using the superefficiency slacks-based measure (SBM). It calculates the environmental efficiency in the presence and absence of the environmental pollution variable respectively, and compares the calculation results of the super-efficiency SBM model with the Banker \& Charnes \& Cooper's (BCC) model, one of the traditional data envelopment analysis (DEA) models. By analyzing the environmental efficiencies in all provinces, it analyzes the slack variables to determine in which direction each region should improve. The results show that the addition of the environmental pollution variable has resulted in significant declines in the efficiencies of provinces with DEA inefficiencies. Among the four regions, the eastern one has the highest environmental efficiency, the western region comes next and the northeastern and central regions are the last ones. There are also some economically developed provinces with low environmental efficiency, and different inefficient provinces need to be improved in different directions.
\end{abstract}

Keywords: DEA, regional environmental efficiency, pollution variable, BCC model, slacks-based measure

\section{Introduction}

The continuous environmental deterioration around the world has become a key factor constraining the sustainable development of all countries in the world. Finding a way to prevent further deterioration of the environment has become a significant issue of concern for the global academic community and governments. For China, the increasingly serious environmental problems have also turned into a major issue affecting China's overall economic development and become a "bottleneck" in its sustainable development path. Therefore, studying how to improve environmental efficiency more effectively is of great significance for promoting the scientific frontier development and helping the government achieve energy conservation and emission reduction targets.

Environmental efficiency is a crucial measure of the environmental conditions in a country (or region). There is still no universal agreement on the definition of environmental efficiency, but it is generally divided into two categories. The first defines the ratio of economic aggregate to environmental load as environmental efficiency (Beukes et al., 2010; Halkos and Tzeremes, 2013; Wang et al., 2007; Zhang, 2008). The environmental load refers to the carrying capacity of the external environment when humans are conducting economic activities, e.g. the carrying capacity of energy, land, general resources, water resources and forest resources, etc. The second definition 
focuses on the perspective of the environmental impact of production activities. In this definition, the environmental efficiency is measured in two ways. First, without considering the efficiency of input, it is measured by the ratio of economic value (GDP) to the impact of environmental pollution, which is the reciprocal of the pollution intensity (Schaltegger and Sturm, 1990; Wang, 2011). The second method considers the efficiencies of both input and output, and it is called comprehensive environmental efficiency or environmental total factor efficiency (Wang et al., 2010; Xu, 2012) or environmental productivity. Obviously, these two definitions of environmental efficiency do not consider the affordability of consumers when pollution is emitted. For example, in densely populated cities, the air pollution emissions impose different environmental impacts than those in the sparsely populated suburbs.

In the measurement of environmental efficiency, Stochastic Frontier Analysis (SFA) (Thijssen, 1999; Tan et al., 2013), Multi-Criteria Decision-Making method (MCDM) (Montanari, 2004), Data Envelopment Analysis (DEA) and other research methods have all been used. Among them, non-parametric methods (such as DEA, etc.) can reduce the subjectivity of the measurement results as there is no need to construct the production function in advance. Therefore, compared with parametric methods (such as SFA), nonparametric methods are more widely used, The DEA method has proven to be a very effective tool to measure the efficiencies and productivities of similar decision-making units (DMUs) and is therefore widely used in industrial, urban, regional, and global productivity and efficiency evaluations. Many scholars have used the DEA model to measure environmental efficiency. Faere et al. (1989) was the first to propose the DEA model for environmental efficiency evaluation. Bevilacqua and Braglia (2002) used the data of seven oil refineries in Italy from 1993 to 1996, selected six indices such as CO, $\mathrm{CO}_{2}, \mathrm{SO}_{2}$ and petroleum processing output, and evaluated the environmental efficiency using the CCR model. Aldanondo et al. (2014) used the DEA model to quantitatively analyze environmental efficiencies of organic agriculture and traditional agriculture in Spain, and concluded that the organic agriculture is more efficient than the traditional one under the same environmental impact. Many scholars have also used DEA to measure the environmental efficiency in China (Chen, 2008; Reinhard et al., 2000; Tone, 2002). Wang et al. (2009) established a DEA efficiency evaluation model, selected data from 28 provinces in China from 2001 to 2005, and measured environmental efficiency from the perspective of environmental regulation. The results show that areas with better environmental efficiencies account for $10 \%$ to $20 \%$. Wu and Ma (2016) used the DEA method to calculate the ecological efficiency of 31 provinces in China from 2009 to 2013, and then used the Tobit model to analyze the factors affecting ecological efficiency. The results show that the per capita GDP and the geographical position of the east have positive impacts on ecological efficiency, while the industrial structure and population density have negative impacts. It can be seen that the DEA method has been widely used to evaluate environmental efficiency. The weight can be determined according to the principle of optimality to calculate the relative efficiency of each DMU, and then the efficiency values and improvement directions of all DMUs can be obtained. However, the radial problem existing in the traditional DEA models affects the accuracy of efficiency evaluation (the technical efficiency of the DMU is 1), and the complete ordering between the evaluated units cannot be addressed. What is more, these models only focus on a single perspective (input or output perspective), which do not fully reflect the actual situation in the excessive investment and production. In order to solve the radial problem in the traditional DEA models, scholars have applied the SBM model, 
the super-efficiency DEA model and a combination of the two to measure the efficiency of various industries. For instance, Yan and Hou (2018) used the super-efficiency SBM model to measure the urban ecological efficiency in China. Zhang and Ma (2018) constructed an efficiency evaluation index system for the urban energy saving and environmental protection industry, based on the principle of the super-efficiency SBM model.

However, most applications of the relevant non-radial model often overlook the environmental efficiency problems that exist in the production process, including environmental pollution.

This paper conducts a comparative study on the measurement of environmental efficiency from the perspective of "environmental impacts of producers' economic activities". It proposes that environmental efficiency is actually the economic efficiency after the environmental factors are taken into account, that is, the economic level achieved at the expense of certain environmental loss. The following innovative research is conducted on this definition: First, this paper uses the entropy weight method to combine undesired outputs (waste gas, wastewater, solid waste) into an indicator to reflect the overall environmental pollution status. Second, this paper fully considers the role of the environmental pollution variable (pollutants) in environmental efficiency, and uses the super-efficiency SBM model to effectively solve the radial problem and the incomplete ordering of units in the traditional model. As a result, the status quo can be more objectively and truly reflected.

The rest of this paper is organized as follows. Section 2 briefly introduces the development of the DEA model, and describes the super-efficiency SBM model used in this paper. Section 3 constructs the input-output index system and comprehensively evaluates environmental pollution indices. Section 4 uses the super-efficiency SBM model to measure the environmental efficiencies of different regions in China, compares them with the measurement results of the BCC model, and analyzes the redundancy rate of input and output. Finally, the conclusions are presented in section 5.

\section{Materials and methods}

Data Envelopment Analysis (DEA) is a non-parametric frontier efficiency analysis method. It was proposed by American operation researchers Chames and Copper in 1978. Their first basic model of DEA is the CCR model, established on the relative efficiency evaluation. After the introduction of this model, many different DEA models emerged. Regarding the concept of "return to scale" in economics research, Banker proposed a BCC model based on variable-scale returns by adding constraints. After many years of development, now the DEA model can be divided into two major categories: radial models and non-radial models. CCR and BCC are radial models (i.e., maintaining quantitative output or input so that inputs or outputs are proportionally reduced or increased). This feature of the radial model makes the result very different from the actual situation. Later, some scholars began to study non-radial models and proposed additive DEA and SBM models. In terms of model improvement, many scholars have made a lot of contributions in enriching relevant theories and practices of DEA.

The basic principle of the DEA model is to treat each individual as a single DMU for evaluation. Many DMUs within a system can be regarded as an evaluation group, and then the overall input-output ratio can be measured. The weight of each input or output 
of a DMU is taken as a variable in the evaluation, so as to determine the efficient production frontier. In the efficiency evaluation, DEA can spontaneously include all data points in the efficiency frontier according to the structural characteristics of the source data, thus saving the prior work like determining the specific function form and improving the process and research efficiency. The relative efficiency (i.e. 1) of all the points on the efficiency frontier represents the highest level, and the relative efficiencies of the remaining points are distributed between 0 and 1 . The calculation results can be obtained according to the efficiency frontier ratio, which is obtained from previous calculation.

\section{Model framework}

\section{CCR model}

The model assumes that there are $\mathrm{n}$ DMUs, each of which has $\mathrm{m}$ input indices and $\mathrm{s}$ output indices, which are similar to the input and output indices in economics. We denote $D_{M U}$ as DMU $j, x_{i j}$ as the ith input of DMU $j$, where $x_{i j}>0 ; y_{r j}$ as the rth output of DMU j, where $y_{r j}>0 ; v_{i}$ as a measure of the ith input, which is also called the weight; $\mathrm{u}_{\mathrm{r}}$ as a measure of the rth output, $\mathrm{i}=1,2,3, \ldots, \mathrm{m} ; \mathrm{j}=1,2,3, \ldots, \mathrm{n} ; \mathrm{r}=1,2,3, \ldots, \mathrm{s}$. For the sake of convenience, let $X_{j}=\left(x_{1 j}, x_{2 j}, x_{3 j}, \ldots x_{m j}\right), j=1,2,3, \ldots, n ; Y_{j}=\left(y_{1 j}, y_{2 j}, y_{3 j}\right.$, $\left.\ldots \mathrm{y}_{\mathrm{sj}}\right), \mathrm{j}=1,2,3, \ldots, \mathrm{n} ; \mathrm{v}=\left(\mathrm{v}_{1}, \mathrm{v}_{2}, \ldots \mathrm{v}_{\mathrm{m}}\right)$; and $\mathrm{u}=\left(\mathrm{u}_{1}, \mathrm{u}_{2}, \ldots \mathrm{u}_{\mathrm{r}}\right)$. Now let us analyze the efficiency evaluation problem of the decision-making unit $\mathrm{DMU}_{\mathrm{j}}$. The fractional model of the CCR model is shown in Equation 1:

$$
\begin{gathered}
\max \frac{\mathrm{u}_{\mathrm{r}} \mathrm{y}_{0}}{\mathrm{v}_{\mathrm{m}} \mathrm{x}_{0}} \\
\text { s.t. } \frac{\mathrm{u}_{\mathrm{r}} \mathrm{y}_{\mathrm{rj}}}{\mathrm{v}_{\mathrm{m}} \mathrm{x}_{\mathrm{mj}}} \leq 1, \mathrm{j}=1,2, \ldots \mathrm{n} \\
\mathrm{u} \geq 0, \mathrm{v} \geq 0
\end{gathered}
$$

Convert the above fractional model to an equivalent linear model Equation 2:

$$
\begin{gathered}
\max _{\mathrm{r}} \mathrm{y}_{\mathrm{r} 0} \\
\text { s.t. } \mathrm{v}_{\mathrm{m}} \mathrm{x}_{\mathrm{i} 0}-\mathrm{u}_{\mathrm{r}} \mathrm{x}_{\mathrm{r} 0} \geq 0, \mathrm{j}=1,2, \ldots \mathrm{n} \\
\mathrm{v}_{\mathrm{m}} \mathrm{x}_{\mathrm{i} 0}=1, \mathrm{v} \geq 0, \mathrm{u} \geq 0
\end{gathered}
$$

The dual programming expression for the above linear programming is shown in Equation 3:

$$
\begin{gathered}
\min \theta-\varepsilon\left(\sum_{\mathrm{i}=1}^{m} s_{i}^{-}+\sum_{r=1}^{s} s_{r}^{+}\right) \\
\text {s.t. } \sum \mathrm{x}_{\mathrm{i}} \lambda_{\mathrm{i}}+\mathrm{s}^{-} \leq \theta \mathrm{x}_{0}, \mathrm{i}=1,2, \ldots \mathrm{m} \\
\sum \mathrm{y}_{\mathrm{j}} \lambda_{\mathrm{j}}-\mathrm{s}^{+} \geq \mathrm{y}_{0}, \mathrm{j}=1,2, \ldots \mathrm{n} \\
\lambda_{\mathrm{j}}, \mathrm{s}^{+}, \mathrm{s}^{-} \geq 0
\end{gathered}
$$


If the optimal solution to Equation 3 is $\left(\lambda^{*}, \theta^{*}, s^{+*}, s^{-*}\right)$, then the following results can be obtained: 1) If $\theta^{*}<1$, the obtained DMU is DEA inefficient; 2) If $\theta^{*}=1$, and $s^{*}$ or $s^{+*}$ is not equal to 0 , then the DMU obtained is DEA weakly efficient; 3 ) If $\theta^{*}=1$, and, $\mathrm{s}^{-*}$ and $s^{+*}$ are equal to 0 , then the DMU obtained is DEA efficient. The above is based on the DEA model with the same input, and the results will be opposite for the output-oriented DEA, which studies the problem of constant input and maximum output.

The premise for the CCR model is that the return to scale is constant, that is, when a DMU is DEA efficient, it is also efficient in technology and scale. Being efficient in technology means that the production is at its best, and the system can use the existing input to get the best output. Being efficient in scale means that production is in a state of constant scale and efficiency. Under this state, if the input is expanded by $\mathrm{N}$ times, the output will also be expanded by $\mathrm{N}$ times.

\section{BCC model}

The BCC model based on the variable-scale premise is expressed in Equation 4 (the following BCC model is input-oriented):

$$
\begin{gathered}
\max \frac{u_{r} y_{r 0}-u_{0}}{v_{m} x_{0}} \\
\text { s.t. } v_{m} x_{j}-u_{r} y_{j}+u_{0} \geq 0, j=1,2, \ldots n \\
v_{m} x_{0}=1, v \geq 0, u \geq 0
\end{gathered}
$$

Its dual model expression is Equation 5:

$$
\begin{gathered}
\min \theta-\varepsilon\left(\sum_{\mathrm{i}=1}^{m} s_{i}^{-}+\sum_{r=1}^{s} s_{r}^{+}\right) \\
\text {s.t. } \sum \mathrm{x}_{\mathrm{i}} \lambda_{\mathrm{i}}+\mathrm{s}^{-} \leq \theta \mathrm{x}_{0}, \mathrm{i}=1,2, \ldots \mathrm{m} \\
\sum \mathrm{y}_{\mathrm{j}} \lambda_{\mathrm{j}}-\mathrm{s}^{+} \geq \mathrm{y}_{0}, \mathrm{j}=1,2, \ldots \mathrm{n} \\
\sum \lambda_{\mathrm{j}}=1 \\
\lambda_{\mathrm{j}} \geq 0, \mathrm{j}=1,2, \ldots \mathrm{n}
\end{gathered}
$$

The BCC model is based on the assumption of variable return to scale (VRS), that is, the impact of scale compensation on efficiency is taken into account in the evaluation of DMUs, so this model can be used to obtain the scale benefits of the DMU, helping decision makers adjust their scale and increase their relative efficiency. Based on this, the input-oriented BCC model is selected to calculate the environmental efficiency. Similar to the CCR model, in this model we can also judge whether the DMU is efficient according to the optimal solution of the model and the value of the slack variable. The specific analysis is as follows: If the optimal solution of Equation 5 is ( $\lambda^{*}$, $\left.\theta^{*}, s^{+*}, s^{*}\right)$, then the following results can be obtained: (1) If $\theta^{*}<1$, the obtained DMU is DEA inefficient; (2) If $\theta^{*}=1$, and $s^{*}$ or $s^{+*}$ is not equal to 0 , the DMU 
obtained is DEA weakly efficient; (3) If $\theta^{*}=1$, and, $s^{* *}$ and $s^{+*}$ are equal to 0 , then the DMU obtained is DEA efficient.

\section{SBM model}

The SBM model (Tone, 2001) solves the efficiency evaluation problem that the units of input or output variables are inconsistent; in other words, this model is units invariant.

$$
\begin{gathered}
\min \rho=\frac{1-\frac{1}{\mathrm{~m}} \sum_{i=1}^{m} \frac{s_{i}^{-}}{x_{i 0}}}{1+\frac{1}{\mathrm{~s}} \sum_{r=1}^{s} \frac{s_{r}^{+}}{y_{r 0}}} \\
\text { s.t. } \sum_{j=1}^{n} \lambda_{j} x_{i j}+s_{i}^{-}=x_{i 0}, \mathrm{i}=1,2, \ldots, \mathrm{m} \\
\sum_{j=1}^{n} \lambda_{j} y_{r j}-s_{\mathrm{r}}^{+}=y_{r 0}, \mathrm{r}=1,2, \ldots, \mathrm{s} \\
\lambda_{j}, s_{i}^{-}, s_{r}^{+} \geq 0, \mathrm{j}=1,2, \ldots, \mathrm{n}
\end{gathered}
$$

The model in Equation 6 is a fractional programming, which can be transformed into the following linear programming form:

$$
\begin{gathered}
\min \tau=\mathrm{t}-\frac{1}{\mathrm{~m}} \sum_{i=1}^{m} \frac{\overline{s_{i}}}{x_{i 0}} \\
\text { s.t.t }+\frac{1}{\mathrm{~s}} \sum_{r=1}^{s} \frac{\bar{s}_{r}^{+}}{y_{r 0}}=1 \\
\sum_{j=1}^{n} \bar{\lambda}_{j} x_{i j}+\bar{s}_{i}^{-}=t x_{i 0}, \mathrm{i}=1,2, \ldots, \mathrm{m} \\
\sum_{j=1}^{n} \bar{\lambda}_{j} y_{r j}-\bar{s}_{i}^{+}=t y_{r 0}, \mathrm{r}=1,2, \ldots, \mathrm{s} \\
\bar{\lambda}_{j}, \bar{s}_{i}, \bar{s}_{r}^{+} \geq 0, \mathrm{j}=1,2, \ldots, \mathrm{n}
\end{gathered}
$$

The optimal solution to linear programming Equation 7 is $\tau^{*}, t^{*}, \bar{\lambda}^{*} \bar{s}^{-*}, \bar{s}^{+*}$. The necessary and sufficient condition for the decision-making unit $D M U$ to be SBM efficient is: $\tau^{*}=1$. The value of the objective function is equal to 1 , which means that all slack variables have a value of 0 ; in other words, there is no excessive input or insufficient output in the evaluated DMU. Similarly, under the assumption of VRS, you only need to add $\sum \lambda_{j}=1$ in the constraints of the model.

\section{Super-efficiency DEA model}

Andersen and Petersen proposed the super-efficiency DEA model to compare the efficiency values of efficient DMUs. This model makes up for the shortcoming of traditional DEA models that efficient DMUs cannot be compared. The super-efficiency 
DEA model obtains the DEA efficiency of each DMU by analyzing the data of input and output indices, and points out the reasons why other DMUs are not DEA efficient and also the direction and extent of optimization.

The evaluation diagrams of the traditional DEA model and the super-efficiency DEA model are shown in Figures 1 and 2.

Figure 1 is the traditional DEA model, where the DMUs that satisfy the DEA are A, $\mathrm{B}, \mathrm{C}$, and $\mathrm{D}$, which constitute the production frontier. Point $\mathrm{E}$ is the DEA inefficient DMU. Take the two DMUs B and E for example. The intersection of the connection between the two points and point $\mathrm{O}$ and the production frontier are respectively $\mathrm{B}_{1}$ and $\mathrm{E}_{1}$. The efficiency value of point $\mathrm{B}$ is $\mathrm{E}_{\mathrm{B}}$ : $\mathrm{OB}_{1} / \mathrm{OB}=1$, and that of point $\mathrm{E}$ is $\mathrm{EE}$ : $\mathrm{OE}_{1} / \mathrm{OE}<1$. Similarly, the efficiency values of the three points $\mathrm{A}, \mathrm{C}$ and $\mathrm{D}$ are also 1 , and the DMU is DEA efficient here. For DEA inefficient DMUs, the efficiency value is less than 1. Figure 2 is the super-efficiency DEA model. It is assumed that ACD constitutes the production frontier. At this time, the efficiency value of point $B$ is $\mathrm{EB}=\mathrm{OB}_{1} / \mathrm{OB}>1$. Similarly, assuming that $\mathrm{ABD}$ constitutes the production frontier, there will also be EC $>1$. Here comes the problem. As points ABCD are all DEA efficient, they still constitute the production frontier, and the efficiency value of the originally inefficient DMU $\mathrm{E}$ is still less than 1.

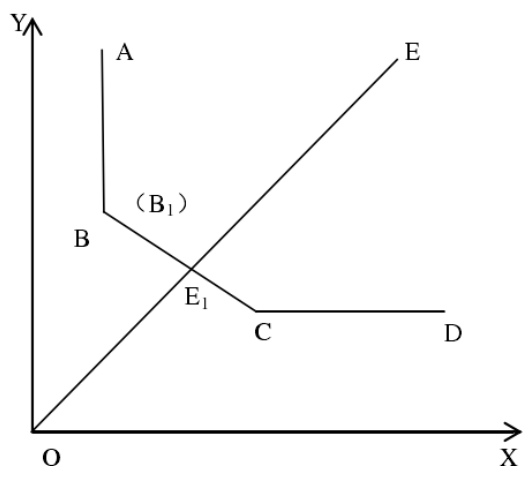

Figure 1. Traditional DEA model

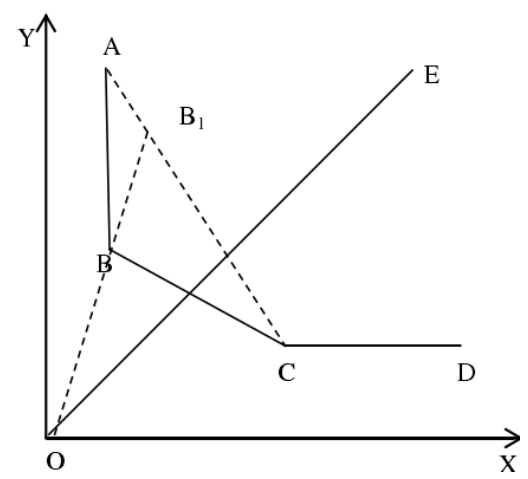

Figure 2. Super efficiency DEA model

\section{Super-efficiency SBM model}

Considering that a DEA efficient DMU will have an efficiency value of 1 in the SBM model, it is impossible to compare multiple efficient DMUs. This is actually a 
sorting problem. The super-efficiency SBM model makes the measurement results closer to reality. It optimizes the slack variable as the objective function (solving the radial problem of the model) and gives the DMU a more reasonable direction for input and output improvement, and in addition, it can be used for sorting the efficiency values of multiple efficient DMUs. The model combines the super-efficiency DEA model and the SBM model. As the input or output orientation will affect the slack of input or output, here the non-oriented model is selected to ensure the rationality of the calculation results.

Under the condition of variable return to scale, the super-efficiency SBM model is as follows:

$$
\begin{gathered}
\rho=\min \frac{\frac{1}{\mathrm{~m}} \sum_{i=1}^{m} \overline{x_{i}} / x_{i k}}{\frac{1}{s} \sum_{r=1}^{s} \overline{y_{r}} / y_{r k}} \\
\text { s.t. } \sum_{\substack{j=1 \\
j \neq k}}^{\mathrm{n}} \lambda_{j} x_{j} \leq \bar{x} ; \sum_{\substack{j=1 \\
j \neq k}}^{\mathrm{n}} \lambda_{j} y_{j} \leq \bar{y} \\
x_{i k}=\sum_{\substack{i=1 \\
j=1}}^{n} x_{i j} \lambda_{j}+s_{i}^{-}, y_{r k}=\sum_{i=1}^{n} y_{r j} \lambda_{j}-s_{r}^{+} \\
\overline{\mathrm{x}} \geq x_{k}, \bar{y} \leq y_{k} \\
\sum_{\substack{\mathrm{j}=1 \\
\mathrm{j} \neq \mathrm{k}}}^{\mathrm{n}} \lambda_{\mathrm{j}}=1, \bar{y} \geq 0, \lambda \geq 0
\end{gathered}
$$

In Equation 8: $\rho$ is the efficiency value, $(\bar{x}, \bar{y})$ the reference point of the decision variable, $s^{-}$the slack variable of the input, $s^{+}$the desired output slack variable, the subscript $\mathrm{k}$ of the variable in the model the kth DMU being evaluated, and $\lambda$ the weight vector. When $\rho<1$, it indicates that the DMU is inefficient. When $\rho>1$, the DMU is in an active state.

This paper uses the superior improved DEA model - the super-efficiency SBM model to evaluate the environmental emission efficiencies of different regions in China to solve the radial problem. The super-efficiency SBM model can also sort the efficient DMUs.

\section{Data collection and processing}

\section{Data description}

Selection of indices: input indices for measuring environmental efficiency include the number of employees at the end of the year, investment in fixed assets, energy consumption and industrial pollution discharge (including wastewater, solid waste and waste gas), etc.; the output index is the total GDP of each province or city. In this paper, three industrial wastes are used as the environmental pollution variable.

This paper selects the data of 30 provinces in China from 2010 to 2015 as samples. Tibet is not included here because its data are unavailable. In addition, the wastewater discharge in 2010 is replaced by industrial wastewater discharge. The original data are extracted from the China Statistical Yearbook, the China Environmental Statistics Yearbook, and the China Energy Statistics Yearbook. The model selected has multiple 
inputs and multiple outputs, with labour, fixed asset investment and energy consumption as the inputs, three wastes (wastewater, industrial waste gas, industrial solid waste) as the environmental pollution variable, and provincial GDP as the desired output. Specific indices selected are elaborated as follows:

(1) Labour input

Labour is an indispensable input factor in economic activities. In environmental efficiency research, labour input should be considered comprehensively in terms of both quantity and quality. Now in the statistical yearbook, most of the labour input is reflected in the quantity, and the labour flow is frequent, which does not reflect labour efficiency. By referring to the existing literatures, this paper uses the number of employed people at the end of each year as the index of labour input.

(2) Energy input

Energy is an essential factor in production activities. In the related research on environmental efficiency, a large number of researchers have gradually considered energy as an input factor into the index system (Mutani et al., 2018; Vand et al., 2018). The rapid economic growth is inseparable from the massive consumption of energy, but the latter is also accompanied by the generation of a large number of pollutants. Therefore, this paper also incorporates energy consumption as an input index into the model to measure environmental efficiency. Here the specific index is the total energy consumption of each province.

(3) Capital input

In some studies, the capital input variable is the capital stock calculated by the perpetual inventory method. There are methods to determine the base capital stock and depreciation, and different methods will result in different results. Therefore, this paper uses capital investment as the capital input. Fixed assets investment plays a vital role in the system, because it can reflect the country's financial policy support. In order to make the data comparable, the capital input data are all converted according to the fixed assets investment index of each province or city into equivalent data in 2010, with the unit being 100 million RMB.

(4) Pollution discharge

Due to the external effects of production, pollutant discharge is inevitable in production activities. Here, this paper refers to Chen (2009) approach: environmental pollution is taken as an input factor. Considering the incomplete data of pollutants in the yearbooks, and the problem that industrial pollutant discharge occupies a large share, this paper comprehensively evaluates the basic data of "three wastes", and uses an entropy weight method to synthesize a comprehensive environmental pollution index as an input variable in the DEA model reflecting the overall pollution status. This is included in the framework of environmental efficiency measurement.

(5) Desired output

The regional GDP reflects the output of production activities in a region during a certain period. This paper follows the traditional practice and uses the GDP of each province as an important index to reflect output. Taking into account the real output results, the nominal GDP of each province and city will be reduced by 2010 and converted into the real GDP reflecting the actual output of the region. Here the GDP data and indices of each province are from China Statistical Yearbook of each year.

The selected input-output indices are explained in Table 1. 
Table 1. Selection of input and output indices

\begin{tabular}{c|c|c}
\hline Index & Variable & Variable declaration \\
\hline \multirow{2}{*}{ Factor input } & Labor input & $\begin{array}{c}\text { Number of working population at the end of the } \\
\text { year in the region }\end{array}$ \\
\cline { 2 - 3 } & Capital input & investment in the fixed assets \\
\cline { 2 - 3 } & Energy consumption & Regional total energy consumption \\
\hline Pollution emission & Industrial pollutant & Environmental pollution composite index \\
\hline Expected output & Regional economic output & Regional GDP \\
\hline
\end{tabular}

\section{Evaluation of the comprehensive environmental pollution index}

In order to reflect the pollutant discharges of provinces and municipalities, according to the records of the pollutant indices in the statistical yearbooks and based on the principles of scienticity, rationality and availability, the index system consists of three indices (industrial waste gas emissions, wastewater discharge and industrial solid waste production) to measure the discharge of pollutants nationwide. The environmental pollution index results are a principal part of the environmental efficiency assessment.

First, considering the dimensionality of the three indices, the normalization method is used to normalize the differences between the indices, with the formula expressed as follows Equation 9:

$$
\mathrm{x}_{\mathrm{ij}}^{\prime}=\frac{x_{i j}-\min x_{j}}{\max x_{j}-\min x_{j}}
$$

where $\mathrm{i}$ denotes each province and $\mathrm{j}$ denotes a pollutant index.

Second, obtain the information entropy of each index Equation 10:

$$
\begin{gathered}
\mathrm{e}_{\mathrm{j}}=-\ln (n)^{-1} \sum_{\mathrm{i}=1}^{\mathrm{n}} p_{i j} \ln p_{i j} \\
\mathrm{p}_{i j}=\frac{x_{i j}^{\prime}}{\sum_{i=1}^{n} x_{i j}^{\prime}}
\end{gathered}
$$

If $p_{i j}=0$, then $p_{i j} \ln p_{i j}=0$.

Third, with the information entropy $e_{j}$ of each index obtained in step 2, the weight of each index is obtained as follows (Eq.11):

$$
w_{j}=\frac{1-e_{j}}{k-\sum e_{j}}
$$

Fourth, the comprehensive environmental pollution index is Equation 12:

$$
E=\sum \mathrm{w}_{\mathrm{j}} \mathrm{p}_{\mathrm{ij}}
$$


Through the above calculations, the results of the comprehensive environmental pollution indices of provinces and municipalities in China in all years are obtained, as shown in Table 2.

Table 2. Comprehensive environmental pollution indices of various provinces and municipalities nationwide from 2010 to 2015

\begin{tabular}{c|c|c|c|c|c|c}
\hline Region & $\mathbf{2 0 1 0}$ & $\mathbf{2 0 1 1}$ & $\mathbf{2 0 1 2}$ & $\mathbf{2 0 1 3}$ & $\mathbf{2 0 1 4}$ & $\mathbf{2 0 1 5}$ \\
\hline Beijing & 0.0912 & 0.0734 & 0.0617 & 0.0532 & 0.0569 & 0.0562 \\
Tianjin & 0.0748 & 0.0590 & 0.0680 & 0.0528 & 0.0621 & 0.0618 \\
Hebei & 0.7464 & 0.7742 & 0.7740 & 0.7834 & 0.7742 & 0.7753 \\
Shanxi & 0.4168 & 0.4225 & 0.4384 & 0.4496 & 0.4519 & 0.4959 \\
Nei Monggol & 0.3499 & 0.3364 & 0.3425 & 0.3097 & 0.3773 & 0.4387 \\
Liaoning & 0.4193 & 0.4405 & 0.4417 & 0.4061 & 0.4767 & 0.5466 \\
Jilin & 0.1327 & 0.1176 & 0.1130 & 0.0975 & 0.1059 & 0.1228 \\
Heilongjiang & 0.1526 & 0.1373 & 0.1448 & 0.1270 & 0.1397 & 0.1540 \\
Shanghai & 0.2071 & 0.1483 & 0.1476 & 0.1338 & 0.1316 & 0.1320 \\
Jiangsu & 0.5396 & 0.5145 & 0.5257 & 0.5078 & 0.5532 & 0.5534 \\
Zhejiang & 0.3452 & 0.2987 & 0.2973 & 0.2773 & 0.2887 & 0.2940 \\
Anhui & 0.2683 & 0.3000 & 0.3131 & 0.2949 & 0.3094 & 0.3412 \\
Fujian & 0.2580 & 0.2150 & 0.2146 & 0.2122 & 0.1952 & 0.1939 \\
Jiangxi & 0.2168 & 0.2233 & 0.2196 & 0.2132 & 0.2170 & 0.2408 \\
Shandong & 0.6123 & 0.5323 & 0.5282 & 0.5159 & 0.5620 & 0.6200 \\
Henan & 0.4054 & 0.4255 & 0.4260 & 0.4274 & 0.4453 & 0.4377 \\
Hubei & 0.2705 & 0.2611 & 0.2486 & 0.2396 & 0.2531 & 0.2700 \\
Hunan & 0.2621 & 0.2393 & 0.2431 & 0.2300 & 0.2228 & 0.2301 \\
Guangdong & 0.5572 & 0.4984 & 0.5002 & 0.4811 & 0.4954 & 0.4992 \\
Guangxi & 0.2907 & 0.2548 & 0.2673 & 0.2145 & 0.2091 & 0.1993 \\
Hainan & 0.0078 & 0.0064 & 0.0064 & 0.0100 & 0.0062 & 0.0058 \\
Chongqing & 0.1348 & 0.1013 & 0.0968 & 0.0946 & 0.0975 & 0.1026 \\
Sichuan & 0.3412 & 0.2990 & 0.3019 & 0.2907 & 0.3129 & 0.2989 \\
Guizhou & 0.1507 & 0.1199 & 0.1437 & 0.1801 & 0.1816 & 0.1661 \\
Yunnan & 0.1847 & 0.2577 & 0.2405 & 0.2312 & 0.2348 & 0.2505 \\
Shaanxi & 0.1841 & 0.1539 & 0.1564 & 0.1544 & 0.1781 & 0.2063 \\
Gansu & 0.0782 & 0.1104 & 0.1203 & 0.0998 & 0.1072 & 0.1161 \\
Qinghai & 0.0299 & 0.1105 & 0.1132 & 0.1043 & 0.1222 & 0.1615 \\
Ningxia & 0.1101 & 0.0642 & 0.0600 & 0.0520 & 0.0679 & 0.0601 \\
Xinjiang & 0.1134 & 0.1063 & 0.1518 & 0.1659 & 0.1774 & 0.1707 \\
\hline & & & & & &
\end{tabular}

As can be seen from Table 2, the heavily polluted areas are concentrated in Hebei, Shanxi, Liaoning, Jiangsu, Shandong and Guangdong, etc. In contrast, Beijing, Tianjin, Hainan and Ningxia, etc. have smaller pollution emissions The comprehensive environmental pollution index is incorporated into the framework of the environmental efficiency assessment, which can fully reflect economic output and environmental pollution. 


\section{Results and discussion}

\section{Estimation of environmental efficiency in various provinces and municipalities}

Traditional DEA models tend to ignore the undesired output indices such as pollutants, when considering the accuracy of evaluation. This imposes certain constraints on the selection and evaluation of indices in environmental efficiency evaluation. In order to visually reflect the impact of pollutant emission indices on environmental efficiency results, both the traditional BCC model and the super-efficiency SBM model are used here for comparison. The BCC model excludes the environmental pollution index, but other input and output indices remain unchanged. Through calculation, the environmental efficiency values of various provinces and municipalities in China from 2010 to 2015 (the data in Tibet are not available) are obtained, as shown in Table 3.

Table 3. Environmental efficiency values of various provinces and municipalities in China from 2010 to 2015

\begin{tabular}{c|c|c|c|c|c|c}
\hline \multirow{2}{*}{ Region } & \multicolumn{2}{|c|}{$\mathbf{2 0 1 0}$} & \multicolumn{2}{|c|}{$\mathbf{2 0 1 1}$} & \multicolumn{2}{|c|}{$\mathbf{2 0 1 2}$} \\
\cline { 2 - 7 } & BCC & SE-SBM & BCC & SE-SBM & BCC & SE-SBM \\
\hline Beijing & 1.000 & 1.2697 & 1.000 & 1.226 & 1.000 & 1.299 \\
Tianjin & 1.000 & 1.0060 & 1.000 & 1.024 & 1.000 & 1.020 \\
Hebei & 0.467 & 0.4095 & 0.484 & 0.385 & 0.490 & 0.378 \\
Shanxi & 0.452 & 0.3480 & 0.403 & 0.321 & 0.404 & 0.305 \\
Nei Monggol & 0.657 & 0.4445 & 0.697 & 0.432 & 0.716 & 0.428 \\
Liaoning & 0.610 & 0.4959 & 0.669 & 0.467 & 0.663 & 0.460 \\
Jilin & 0.515 & 0.4604 & 0.498 & 0.475 & 0.517 & 0.464 \\
Heilongjiang & 0.523 & 0.4672 & 0.506 & 0.460 & 0.466 & 0.423 \\
Shanghai & 1.000 & 1.1548 & 1.000 & 1.184 & 1.000 & 1.200 \\
Jiangsu & 1.000 & 1.0187 & 1.000 & 1.026 & 1.000 & 1.033 \\
Zhejiang & 0.956 & 0.8494 & 0.938 & 0.839 & 0.939 & 0.811 \\
Anhui & 0.627 & 0.3895 & 0.608 & 0.373 & 0.605 & 0.358 \\
Fujian & 0.749 & 0.5808 & 0.730 & 0.565 & 0.744 & 0.553 \\
Jiangxi & 0.737 & 0.4299 & 0.704 & 0.417 & 0.713 & 0.411 \\
Shandong & 0.822 & 0.6821 & 0.829 & 0.687 & 0.829 & 0.685 \\
Henan & 0.586 & 0.5076 & 0.582 & 0.495 & 0.595 & 0.489 \\
Hubei & 0.563 & 0.4794 & 0.529 & 0.468 & 0.531 & 0.466 \\
Hunan & 0.589 & 0.4897 & 0.547 & 0.477 & 0.555 & 0.472 \\
Guangdong & 1.000 & 1.2451 & 1.000 & 1.260 & 1.000 & 1.278 \\
Guangxi & 0.595 & 0.3920 & 0.574 & 0.382 & 0.571 & 0.371 \\
Hainan & 1.000 & 2.0915 & 1.000 & 3.711 & 1.000 & 3.535 \\
Chongqing & 0.497 & 0.4267 & 0.482 & 0.445 & 0.515 & 0.445 \\
Sichuan & 0.496 & 0.4239 & 0.494 & 0.442 & 0.511 & 0.447 \\
Guizhou & 0.489 & 0.3378 & 0.353 & 0.301 & 0.316 & 0.263 \\
Yunnan & 0.459 & 0.3385 & 0.437 & 0.307 & 0.411 & 0.297 \\
Shaanxi & 0.562 & 0.4401 & 0.542 & 0.436 & 0.535 & 0.420 \\
Gansu & 0.447 & 0.3720 & 0.392 & 0.313 & 0.360 & 0.287 \\
Qinghai & 1.000 & 1.1678 & 1.000 & 1.101 & 1.000 & 1.098 \\
Ningxia & 0.887 & 0.6952 & 0.881 & 1.027 & 0.890 & 1.038 \\
Xinjiang & 0.511 & 0.4586 & 0.407 & 0.389 & 0.406 & 0.332 \\
\hline & & & & & & \\
\hline
\end{tabular}


Table 3. cont. Environmental efficiency values of various provinces and municipalities in China from 2010 to 2015

\begin{tabular}{c|c|c|c|c|c|c}
\hline \multirow{2}{*}{ Region } & \multicolumn{2}{|c|}{$\mathbf{2 0 1 3}$} & \multicolumn{2}{|c|}{$\mathbf{2 0 1 4}$} & \multicolumn{2}{|c}{$\mathbf{2 0 1 5}$} \\
\cline { 2 - 7 } & $\mathbf{B C C}$ & SE-SBM & BCC & SE-SBM & BCC & SE-SBM \\
\hline Beijing & 1.000 & 1.316 & 1.000 & 1.289 & 1.000 & 1.298 \\
Tianjin & 1.000 & 1.027 & 1.000 & 1.026 & 1.000 & 1.031 \\
Hebei & 0.479 & 0.382 & 0.479 & 0.377 & 0.470 & 0.377 \\
Shanxi & 0.398 & 0.299 & 0.388 & 0.282 & 0.367 & 0.272 \\
Nei Monggol & 0.717 & 0.423 & 0.728 & 0.391 & 0.726 & 0.429 \\
Liaoning & 0.660 & 0.485 & 0.667 & 0.467 & 0.625 & 0.484 \\
Jilin & 0.536 & 0.475 & 0.546 & 0.460 & 0.562 & 0.448 \\
Heilongjiang & 0.460 & 0.417 & 0.494 & 0.428 & 0.501 & 0.432 \\
Shanghai & 1.000 & 1.152 & 1.000 & 1.149 & 1.000 & 1.165 \\
Jiangsu & 1.000 & 1.045 & 1.000 & 1.052 & 1.000 & 1.055 \\
Zhejiang & 0.901 & 0.796 & 0.908 & 0.790 & 0.892 & 0.796 \\
Anhui & 0.564 & 0.343 & 0.568 & 0.336 & 0.568 & 0.335 \\
Fujian & 0.739 & 0.546 & 0.734 & 0.552 & 0.745 & 0.561 \\
Jiangxi & 0.651 & 0.390 & 0.637 & 0.380 & 0.622 & 0.371 \\
Shandong & 0.823 & 0.706 & 0.826 & 0.705 & 0.822 & 0.685 \\
Henan & 0.624 & 0.487 & 0.625 & 0.484 & 0.631 & 0.486 \\
Hubei & 0.580 & 0.477 & 0.587 & 0.478 & 0.601 & 0.483 \\
Hunan & 0.607 & 0.486 & 0.620 & 0.497 & 0.629 & 0.501 \\
Guangdong & 1.000 & 1.273 & 1.000 & 1.266 & 1.000 & 1.249 \\
Guangxi & 0.550 & 0.367 & 0.541 & 0.360 & 0.535 & 0.358 \\
Hainan & 1.000 & 2.506 & 1.000 & 3.922 & 1.000 & 3.810 \\
Chongqing & 0.556 & 0.454 & 0.564 & 0.448 & 0.565 & 0.454 \\
Sichuan & 0.534 & 0.454 & 0.536 & 0.450 & 0.545 & 0.462 \\
Guizhou & 0.316 & 0.245 & 0.294 & 0.237 & 0.288 & 0.239 \\
Yunnan & 0.399 & 0.291 & 0.387 & 0.281 & 0.399 & 0.280 \\
Shaanxi & 0.517 & 0.408 & 0.517 & 0.394 & 0.506 & 0.391 \\
Gansu & 0.326 & 0.271 & 0.301 & 0.256 & 0.306 & 0.254 \\
Qinghai & 1.000 & 1.110 & 1.000 & 1.108 & 1.000 & 1.114 \\
Ningxia & 0.859 & 1.053 & 0.866 & 1.045 & 0.852 & 1.077 \\
Xinjiang & 0.402 & 0.308 & 0.410 & 0.279 & 0.405 & 0.276 \\
\hline & & & & & &
\end{tabular}

It can be seen from the above table that the environmental efficiency was not balanced in China, and during the investigation period, the extreme difference in environmental efficiency was expanding year by year. The provinces (municipalities) with an efficiency of greater than 1 during the investigation period are Beijing, Tianjin, Qinghai, Shanghai, Guangdong, Hainan and Jiangsu, where the economic environment is relatively stable, and most of which are eastern provinces, with high investments in pollution control; the provinces ranking last in terms of environmental efficiency are Guizhou, Gansu, Shanxi, Yunnan and Xinjiang. This paper analyzes the differences between economic efficiency and environmental efficiency, and the comparison results are shown in the above table. It should be noted that when the relative efficiency evaluation value of the DEA is 1, the DMU is DEA efficient; and when the relative 
efficiency is less than 1, the DMU is DEA inefficient. Through comparative analysis, the following two conclusions are obtained:

First, the BCC model does not contain any undesired output. Among the evaluation results, 7 DMUs have an economic efficiency of 1, which cannot be further compared, while the super-efficiency SBM model takes the environmental pollution variable into account. It can be seen that there are 7 DMUs that achieve an efficiency value of greater than 1 , thus they can be further compared.

Second, after the environmental pollution index is taken into account, except for 6 areas like Hainan, Qinghai, Shanghai and Jiangsu whose environmental efficiencies are all greater than 1, the other 24 DEA inefficient areas see significant declines in the efficiency values: the annual average interval of the BCC model for environmental pollution variable is [0.590, 0.617], and the annual average interval for the superefficiency SBM model with the environmental pollution variable is [0.440, 0.497]. Figure 3 compares the calculation results of the two models in 2015. It can be clearly seen that the evaluation efficiencies in the super-efficiency SBM model are all lower than those in the BCC model, except those of the DEA efficient DMUs. If Beijing, Shanghai, Hainan and other provinces in the efficiency frontier are used as benchmarks, there will be a lot to improve in Shanxi, Guizhou and Yunnan with the same input and output. This shows that there are significant gaps in environmental efficiency among provinces, and the lower the efficiency value, the greater the potential for improvement.

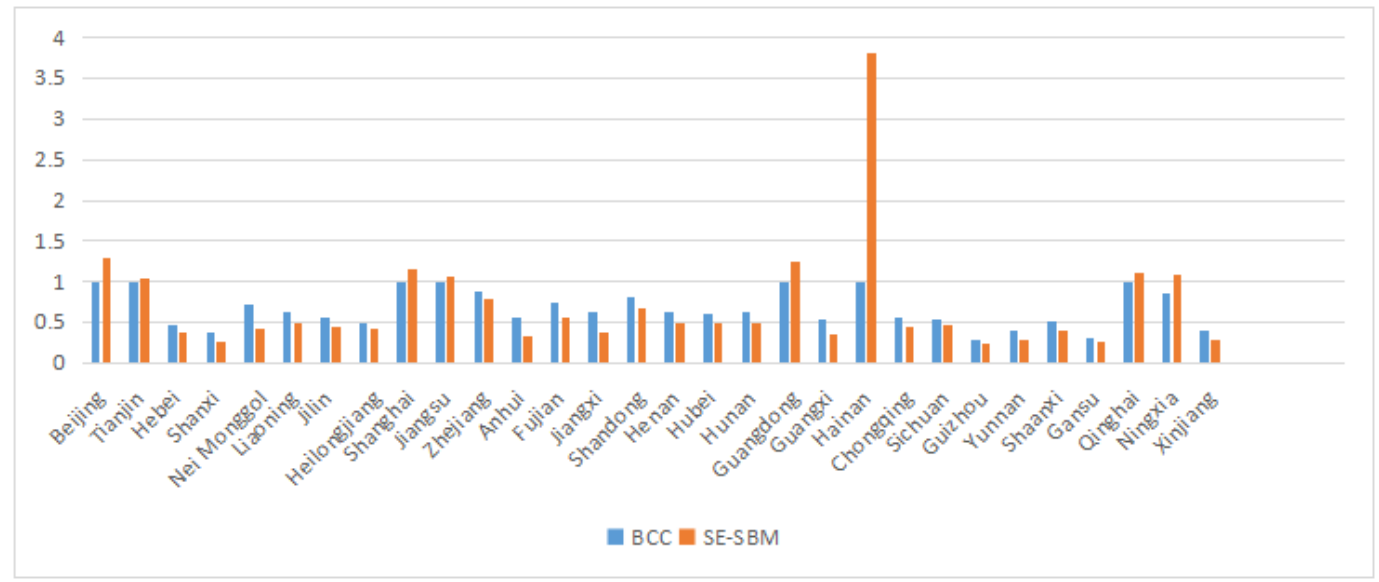

Figure 3. Overview of environmental efficiency in provinces and municipalities of China in 2015

To a certain extent, the above results reflect the actual differences in the transformation of the production capacity into environmental efficiency by various provinces and municipalities in China. On the whole, the environmental efficiency performance of the provinces and municipalities in China is generally not good, except for a few regions, which have achieved relatively high environmental efficiencies thanks to the long-term economic accumulation. China has a vast territory, where the regional location and factor endowments vary greatly among provinces and municipalities, so the gaps between environmental efficiency are inevitable and also reasonable. Under the new concept of economic development, it is necessary to improve the regional economy and reduce the damages to the environment. In addition to the above reasons, low-efficiency areas blindly pursue high output without considering the 
environmental tolerance, which also cause environmental inefficiency. Therefore, China still has a long way to go in terms of environmental efficiency improvement.

Considering that there are a few large extremum values in the super-efficiency SBM model, the provinces and municipalities with efficiency values greater than or equal to 1 during the investigation period are excluded, and only the differences in the efficiency of economic output and the efficiency of environmental pollution variable are taken into account. From Table 4, it can be seen that the efficiency value in the super-efficiency model sees a significant reduction, indicating that the addition of the environmental pollution index has great negative impact on the efficiency value. Nevertheless, the reduction in efficiency shows a decreasing trend year by year, indicating that the national economic level is improving. At the same time, the environmental quality is also showing a good trend, and the environmental efficiency value considering the environmental pollution variable is getting closer to that without considering the environmental pollution variable. The gaps are being gradually narrowed because during 2011-2015, i.e. the $12^{\text {th }}$ five-year period, China put more emphasis on the ecological civilization construction and developed and implemented strict emission reduction measures and regulations in the production activities under the 12th Five-Year Plan, which greatly improved the awareness of environmental protection in this country.

Table 4. Comparison of the results of the BCC model and the super-efficiency SBM model

\begin{tabular}{c|c|c|c|c|c|c}
\hline Year & $\mathbf{2 0 1 0}$ & $\mathbf{2 0 1 1}$ & $\mathbf{2 0 1 2}$ & $\mathbf{2 0 1 3}$ & $\mathbf{2 0 1 4}$ & $\mathbf{2 0 1 5}$ \\
\hline BCC & 0.5998 & 0.5777 & 0.5775 & 0.5738 & 0.5749 & 0.5723 \\
SE-SBM & 0.4747 & 0.4489 & 0.4348 & 0.4323 & 0.4241 & 0.4261 \\
D-value & 0.1251 & 0.1288 & 0.1427 & 0.1415 & 0.1508 & 0.1462 \\
\hline
\end{tabular}

\section{Differences in efficiency levels among the four regions}

Due to geographical reasons, there are large differences in environmental efficiency between regions. According to the regional data from the National Bureau of Statistics, this paper divides the provinces and municipalities in China into four regions, namely the eastern region, including Beijing, Fujian, Guangdong, Hebei, Jiangsu, Shandong, Shanghai, Tianjin, Hainan and Zhejiang; the central region, including Anhui, Henan, Hunan, Jiangxi, Hubei and Shanxi; the western region, including Gansu, Guangxi, Guizhou, Inner Mongolia, Ningxia, Qinghai, Shaanxi, Chongqing, Sichuan, Xinjiang, Tibet and Yunnan; the northeastern region, including Heilongjiang, Jilin, and Liaoning. In this paper, Tibet is not included due to lack of data. The average environmental efficiencies of the four major regions in the major years are compared with the national level, as shown in Table 5.

Table 5. Environmental efficiency mean values of major years in four major regions

\begin{tabular}{c|c|c|c|c|c|c}
\hline Year & $\mathbf{2 0 1 0}$ & $\mathbf{2 0 1 1}$ & $\mathbf{2 0 1 2}$ & $\mathbf{2 0 1 3}$ & $\mathbf{2 0 1 4}$ & $\mathbf{2 0 1 5}$ \\
\hline Region & 1.0308 & 1.1906 & 1.1792 & 1.075 & 1.2128 & 1.2026 \\
Eorthern & 0.4745 & 0.4673 & 0.4491 & 0.4589 & 0.4513 & 0.4548 \\
Central & 0.4407 & 0.4253 & 0.4169 & 0.4136 & 0.4096 & 0.4079 \\
Western & 0.4997 & 0.5067 & 0.4934 & 0.4895 & 0.4771 & 0.485 \\
Nationwide & 0.6624 & 0.7144 & 0.7023 & 0.6664 & 0.7062 & 0.7058 \\
\hline
\end{tabular}


Table 6 shows that the environmental efficiencies of the above several regions in China are quite different - the efficiency value in the eastern region is [1.03, 1.22], the central region $[0.40,0.45]$, the western region $[0.47,0.51]$, the northeast region $[0.44$, $0.48]$ and the national level $[0.66,0.72]$. Despite a few inefficient provinces, the efficiency value in the eastern region is much higher than those in the other three regions and the national average; on the other hand, the environmental efficiencies of the western region, the northeast region and the central region are all lower than the national average.

Table 6. Analysis of input and output redundancy of environmental efficiency in provinces and municipalities of China in 2015

\begin{tabular}{|c|c|c|c|c|c|c|}
\hline DMU & Reference set & $\begin{array}{l}\text { Number of } \\
\text { employees }\end{array}$ & $\begin{array}{c}\text { Energy } \\
\text { consumption }\end{array}$ & $\begin{array}{l}\text { Fixed asset } \\
\text { investment }\end{array}$ & $\begin{array}{l}\text { Environmental } \\
\text { pollution index }\end{array}$ & $\begin{array}{c}\text { Regional } \\
\text { GDP }\end{array}$ \\
\hline Beijing & $\begin{array}{l}\text { Tianjin, } \\
\text { Shanghai, } \\
\text { Hainan }\end{array}$ & -28.546 & 2749.201 & 0 & 0.044 & 0 \\
\hline Tianjin & $\begin{array}{l}\text { Beijing, } \\
\text { Shanghai, } \\
\text { Ningxia }\end{array}$ & 110.811 & -1461 & -4984.455 & 0 & 0 \\
\hline Hebei & $\begin{array}{l}\text { Shanghai, } \\
\text { Guangdong }\end{array}$ & -2195.15 & -15475.072 & -19300.051 & -0.594 & 0 \\
\hline Shanxi & Beijing & -687 & -12531 & -6230.685 & -0.44 & 6816.804 \\
\hline Nei Monggol & Beijing & -278 & -12074 & -5844 & -0.382 & 1474.195 \\
\hline Liaoning & $\begin{array}{l}\text { Shanghai, } \\
\text { Guangdong }\end{array}$ & -801.312 & -9327.276 & -9806.287 & -0.396 & 0 \\
\hline Jilin & Beijing & -295 & -1289 & -5073.682 & -0.067 & 6754.161 \\
\hline Heilongjiang & Beijing & -849 & -5273 & -2302.637 & -0.098 & 4858.581 \\
\hline Shanghai & $\begin{array}{c}\text { Beijing, } \\
\text { Guangdong }\end{array}$ & 266.56 & -2485.894 & 2850.598 & -0.037 & 0 \\
\hline Jiangsu & $\begin{array}{l}\text { Shanghai, } \\
\text { Guangdong }\end{array}$ & 1052.741 & -1662.856 & -18937.337 & -0.085 & 0 \\
\hline Zhejiang & $\begin{array}{c}\text { Beijing, } \\
\text { Guangdong }\end{array}$ & -412.985 & -2876.456 & -10217.698 & -0.05 & 0 \\
\hline Anhui & $\begin{array}{c}\text { Beijing, } \\
\text { Guangdong }\end{array}$ & -3124.258 & -5332.103 & -15624.926 & -0.282 & 0 \\
\hline Fujian & $\begin{array}{c}\text { Beijing, } \\
\text { Guangdong }\end{array}$ & -1147.921 & -3318.144 & -11283.023 & -0.099 & 0 \\
\hline Jiangxi & Beijing & -1430 & -1587 & -9145.104 & -0.185 & 4746.947 \\
\hline Shandong & $\begin{array}{c}\text { Beijing, } \\
\text { Guangdong }\end{array}$ & -1218.132 & -11521.409 & -21100.034 & -0.192 & 0 \\
\hline Henan & $\begin{array}{c}\text { Beijing, } \\
\text { Guangdong }\end{array}$ & -3774.24 & -8552.825 & -19667.714 & -0.234 & 0 \\
\hline Hubei & $\begin{array}{c}\text { Beijing, } \\
\text { Guangdong }\end{array}$ & -1823.084 & -6547.908 & -14263.017 & -0.157 & 0 \\
\hline Hunan & $\begin{array}{c}\text { Beijing, } \\
\text { Guangdong }\end{array}$ & -2172.16 & -5738.215 & -12524.51 & -0.119 & 0 \\
\hline Guangdong & Jiangsu & -1460 & 90 & 17120.606 & 0.054 & -3738.185 \\
\hline Guangxi & Beijing & -1634 & -2908 & -7936.452 & -0.143 & 4838.593 \\
\hline
\end{tabular}




\begin{tabular}{c|c|c|c|c|c|c}
\hline Hainan & $\begin{array}{c}\text { Beijing, } \\
\text { Ningxia }\end{array}$ & -168.807 & 3511.272 & 192.264 & 0.054 & 0 \\
\hline Chongqing & Beijing & -521 & -2081 & -6270.042 & -0.046 & 5811.257 \\
\hline Sichuan & $\begin{array}{c}\text { Beijing, } \\
\text { Guangdong }\end{array}$ & -2800.317 & -9051.883 & -13611.917 & -0.167 & 0 \\
\hline Guizhou & Beijing & -761 & -3095 & -3012.665 & -0.11 & 12002.69 \\
\hline Yunnan & Beijing & -1756 & -3504 & -5398.654 & -0.194 & 8072.753 \\
\hline Shaanxi & Beijing & -885 & -4863 & -9605.846 & -0.15 & 3194.829 \\
\hline Gansu & Beijing & -350 & -670 & -1160.211 & -0.06 & 13490.221 \\
\hline Qinghai & $\begin{array}{l}\text { Hainan, } \\
\text { Ningxia }\end{array}$ & 112.12 & 0 & 315.671 & -0.121 & 648.559 \\
\hline Ningxia & $\begin{array}{l}\text { Hainan, } \\
\text { Qinghai }\end{array}$ & 112.115 & -2701.808 & -166.791 & 0 & 193.215 \\
\hline Xinjiang & Beijing & -9 & -8798 & -2948.25 & -0.114 & 11237.835 \\
\hline
\end{tabular}

\section{Redundancy analysis of input and output}

If the efficiency of a DMU is less than 1, then it is DEA inefficient. The reasons why it is different from the DMUs in the frontier include excessive input, excessive undesired output and insufficient desired output. The super-efficiency SBM model adds slack variables to the objective function to provide information on the input and output redundancy of each DMU, and clearly points out the direction for efficiency improvement. Input redundancy includes fixed asset investment, labour force population, total energy consumption and environmental pollution index. The desired output redundancy is expressed in GDP. Section 3 of this paper uses the superefficiency SBM model to measure the environmental efficiency values of 30 provinces in China from 2010 to 2015. This section takes the redundancy of input and output of environmental efficiency in various provinces and municipalities in China in 2015 for example.

In Table 6, we list the improvement goals for each province (negative data indicate the required reductions). From this table, it can be seen that the provinces and municipalities with lower efficiencies have the problems like excessive investment, insufficient output, unreasonable input of factors, insufficient control of environmental pollution and less-than-desired output. Those with high environmental efficiencies also require efficiency improvement. For example, Jiangsu has met the requirement in terms of economic output, so there is no need for improvement in this area, but compared with Shanghai and Guangdong, it still needs to reduce energy consumption, fixed asset investment and control of environmental pollution (by respectively 1662.856, 18937.337 and 0.085). So with Shanghai and Guangdong as the frontiers, Jiangsu needs to impose reasonable control over the input factors to achieve the optimal level of efficiency.

This paper also conducts more detailed and in-depth analysis of the input and output redundancy of each region. In terms of labour, Tianjin, Shanghai, Jiangsu, Qinghai, and Ningxia need to increase their input, and the remaining provinces and municipalities need to reduce it. Excessive labour input will hinder regional economic growth and also put pressure on the environment. In reality, it is not feasible to reduce the population of labour force, so this requires more rational allocation of labour resources. It is important to improve the quality of the labour force and implement the people-oriented social 
development concept. In terms of energy consumption, except the four regions Beijing, Guangdong, Hainan and Qinghai, all provinces and municipalities need reductions. Energy consumption is accompanied by the generation of large amounts of pollutants, so controlling energy consumption is an important way to improve environmental efficiency. As the "fuel" to the social and economic development, energy is essential to the economic growth. Under the current severe energy consumption situation, a lot of effort needs to be made in the energy structure adjustment so as to better control energy consumption and reduce emissions. In terms of fixed assets investment, Qinghai, Hainan, Guangdong and Shanghai need moderate increases, while the other provinces have excessive investment in fixed assets. This shows that the capital investment does not conform to its own actual development in many provinces of China, manifested in unreasonable investment and utilization. Similarly, in terms of the environmental pollution index, most provinces do not have good performances they all need to reduce the pollution index and control the pollutant emissions. In terms of the desired output, $50 \%$ of the provinces do not need to increase GDP, and the total GDP of these regions rank high.

\section{Conclusion}

This paper firstly introduces the concept of environmental efficiency, selects the input and output indices of environmental efficiency, and then uses the super-efficiency SBM model considering environmental pollution to measure the environmental efficiency of 30 provinces and municipalities in China from 2010 to 2015.

It can be concluded that the addition of the environmental pollution variable results in significant declines in the efficiencies of DEA inefficient provinces. The overall environmental efficiency in China is low, and the environmental efficiencies of the four regions vary significantly. The areas with high environmental efficiencies fall into two categories: the first are the economically developed provinces in the eastern coastal region, which all have solid economic bases; the second are remote provinces, such as Qinghai and Ningxia in the western region, with small economic aggregate and low environmental pollution. The economic advantage obviously plays a greater role in the evaluation of environmental efficiency, and it is scattered nationwide - Beijing-Tianjin region, Yangtze River Delta region, and Pearl River region, which are consistent with the urban agglomerations in the developed regions of China. The areas with good natural environment and low economic levels represented by Qinghai and Ningxia are examples of high environmental efficiency. These areas focus on the coordinated development of the economic environment. Those that need to improve environmental efficiency include: provinces with regional economic characteristics, such as Fujian and Shandong; and the central and western provinces with obvious industrial characteristics and serious environmental pollution. From the above analysis, it can be seen that the environmental efficiencies of the provinces and municipalities vary greatly, and judging from the data every year, the gaps are gradually increasing.

Through comparative analysis of the four regions, it is found that the environmental efficiency in the eastern region is much higher than those of the other three regions. The overall economic level in the eastern region is high and the pollution control is also better than that in the others. The northeastern and central regions have similarly low environmental efficiencies. Due to the vast territory of the western region, the environmental efficiencies of the provinces there vary greatly, but the overall 
environmental efficiency level is better than that in the northeastern and central regions. In terms of environmental efficiency gaps, the difference in the eastern region has been large for many years, those in the northeastern and central regions are maintained at a low level, and that in the western region is increasing year by year, indicating that the gaps are generally expanding in China, which is a bad signal for the coordination between the economy and the environment.

Improper behaviours in production activities should be cut off from the source, rather than be remedied afterwards. The government should play the positive role of economic resources, rationally plan the utilization of investments in environmental protection, and guide enterprises to carry out energy conservation and pollution reduction. Judging from the current situation, the policy environment in China has not yet reached the desired level, and thus it is necessary to build an intellectual property protection system and a fair competition system. At present, the economic development is not balanced among different regions of China. Each region should rationally adjust the proportions of the three major industries in light of its own situation. The central and western regions rely mainly on the secondary industry, which hinders the development of new economic growth points. In order to improve the economic environment and make the regional industries more competitive, enterprises with "high energy consumption and low production" should be restricted and green and low-carbon recycling industries with high added value should be vigorously developed.

In the follow-up study, further exploration and research are needed in the following aspects. (1) The research on the region can further deepen to the prefecture-level city and county level, and expand the research perspective on environmental efficiency measurement. (2) With the continuous improvement of statistical data, the consumer's tolerance for pollution emissions should be included in the research field to further enrich the content of environmental efficiency measurement. (3) This paper considers the macro level more. The follow-up research can analyze the environmental efficiency from a smaller micro level, such as the corporate governance structure and enterprise property rights arrangement.

Acknowledgements. This paper is supported by the Philosophy Social Science Foundation of Zhejiang Province (19NDJC198YB), Natural Science Foundation of China (71403247; 71673250), First Class Discipline of Zhejiang-A (Zhejiang Gongshang University-Statistics), Zhejiang province advantage subject (Zhejiang Gongshang University-Statistics), Zhejiang Statistical Science Project, and the graduate innovation project of Zhejiang Gongshang University.

\section{REFERENCES}

[1] Aldanondo-Ochoa, A. M., Casasnovas-Oliva, V. L., Arandia-Miura, A. (2014): Environmental efficiency and the impact of regulation in dryland organic vine production. - Land Use Policy 36: 275-284.

[2] Beukes, P. C., Gregorini, P., Romera, A. J., Levy, G., Waghorn, G. C. (2010): Improving production efficiency as a strategy to mitigate greenhouse gas emissions on pastoral dairy farms in New Zealand. - Agriculture Ecosystems \& Environment 136(3): 358-365.

[3] Bevilacqua, M., Braglia, M. (2002): Environmental efficiency analysis for Eni oil refineries. - Journal of Cleaner Production 10(1): 85-92.

[4] Chen, A. (2008): Evaluation of China's regional ecological efficiency and its influencing factors: a case study of interprovincial data from 2000 to 2006. - Chinese Journal of Management Science S1: 566-570. 
[5] Chen, S. Y. (2009): Energy consumption, carbon dioxide emissions and sustainable development of China's industry. - Economic Research Journal (4): 41-55.

[6] Faere, R., Grosskopf, S., Lovell, C. A. K., Pasurka, C. (1989): Multilateral productivity comparisons when some outputs are undesirable: a nonparametric approach. - The Review of Economics and Statistics 71(1): 90.

[7] Halkos, G. E., Tzeremes, N. G. (2013): A conditional directional distance function approach for measuring regional environmental efficiency: evidence from UK regions. European Journal of Operational Research 227(1): 182-189.

[8] Montanari, R. (2004): Environmental efficiency analysis for Enel thermo-power plants. Journal of Cleaner Production 12(4): 403-414.

[9] Mutani, G., Fontanive, M., Arboit, M. E. (2018): Energy-use modelling for residential buildings in the metropolitan area of Gran Mendoza (AR). - Tecnica Italiana - Italian Journal of Engineering Science 61+1(2): 74-82.

[10] Reinhard, S., Lovell, C. A. K., Thijssen, G. J. (2000): Environmental efficiency with multiple environmentally detrimental variables; estimated with SFA and DEA. European Journal of Operational Research 121(2): 287-303.

[11] Schaltegger, S., Sturm, A. (1990): Environmental rationality. - Die Unternehmung 4: 117-131.

[12] Tan, X., Cao, Y. Q., Shi, L., Zheng, S. Y., Ma, Z. (2013): Comparative study on environmental efficiency in the three northeastern provinces: 1991-2010. - Productivity Research 4: 109-112.

[13] Thijssen, G. (1999): Econometric estimation of technical and environmental efficiency: an application to Dutch dairy farms. - American Journal of Agricultural Economics 81(1): 44-60.

[14] Tone, K. (2001): A slacks-based measure of efficiency in data envelopment analysis. European Journal of Operational Research 130(3): 498-509.

[15] Tone, K. (2002): A slacks-based measure of super-efficiency in data envelopment analysis. - European Journal of Operational Research 143(1): 32-41.

[16] Vand, A. Z., Mirzaei, M., Ahmadi, M. H., Lorenzini, G., Kumar, R., Jilte, R. (2018): Technical and economical optimization of CHP systems by using gas turbine and energy recovery system. - Mathematical Modelling of Engineering Problems 5(4): 286-292.

[17] Wang, B., Wu, Y., Yan, P. (2010): Environmental efficiency and environmental total factor productivity growth in China's regional economies. - Economic Research Journal 45(5): 95-109.

[18] Wang, D. P., Zhu, Y. C. (2011): Dynamic evaluation of water environmental efficiency in China's seven river basins. - China Population, Resources and Environment 21: 9.

[19] Wang, Q., Gu, X. W., Wang, J., Ding, Y. (2007): Research on environmental load and environmental efficiency in China. - Journal of Northeastern University 28(4): 589-591.

[20] Wang, Q. W., Zhou, D. Q., Chen, H. T. (2009): Technological progress and energy efficiency: an analysis based on the ARDL method. - Journal of Applied Statistics and Management 28(5): 913-920.

[21] Wu, M. R., Ma, J. (2016): Analysis of China's regional ecological efficiency measurement and its influencing factors - based on the DEA-Tobit two-step method. Technology Economics 35(3): 75-80.

[22] Xu, Y. J. (2012): Research on environmental efficiency and environmental total factor productivity of China's industrial sector. - Journal of Renmin University of China in Chinese 20-67.

[23] Yan, J. Y., Hou, M. Y. (2018): Study on the technical efficiency and time-space distribution of China's mineral resources industry chain. - China Mining Magazine (2): 65-69.

[24] Zhang, J. L. (2008): Research on eco-economic efficiency evaluation of production enterprises. - Central South University: phd thesis. 
[25] Zhang, X. M., Ma, P. Q. (2018): Research on efficiency evaluation and comparison of urban energy saving and environmental protection industry based on super-efficiency SBM model: a case study of Lanzhou City. - Science and Technology Management Research 38: 268-274. 